\title{
Investigasi Keandalan Struktur Beton Bertulang Dengan Alat Pundit Lab Pada Bangunan Gedung Penunjang Pendidikan
}

\author{
Ery Radya Juarti , Yullianty Noorlaelasari \\ Staf Pengajar Jurusan Teknik Sipil Politeknik Negeri Bandung \\ Jl.Gegerkalong Hilir Ds.Ciwaruga Bandung 40012, \\ E-mail:ery_rj@yahoo.com,E-mail:nr_yullianty@yahoo.co.id
}

\begin{abstract}
ABSTRAK
Politeknik memiliki bangunan fisik yang fungsinya sangat strategis dalam melayani kepentingan pendidikan vokasi. Namun demikian usia bangunan yang cukup tua,pemanfaatan bangunan untuk bengkel dan laboratorium serta pemeliharaan yang ala kadarnya, mengakibatkan bangunan banyak mengalami kerusakan. Perlu dilakukan pemeriksaan dan pengujian terhadap material pembentuk struktur bangunan gedung untuk mengetahui ketahanan kontruksi bangunan gedung selama masa layan tertentu. Pada penelitian ini dilakukan pengujian tidak merusak dengan Metode Ultrasonic Pulse Velocity (UPV), dengan menggunakan alat "Proceq Pundit Lab"untuk mengetahui kualitas mutu material beton pada elemen kolom dan balok bangunan gedung. Lokasi pengambilan data di Politeknik Pos dilaksanakan pada 2 (dua) lokasi, yaitu pada bangunan Gedung Rektorat dan Gedung Pendidikan masing-masing terdiri dari 3 lantai. Pada bangunan gedung Politeknik Manufaktur dilaksanakan di 1 (satu) lokasi, yang terdiri dari Gedung Rektorat, Gedung Kuliah dan Gedung Administrasi. Sedangkan pada bangunan gedung Politeknik Negeri Bandung dilaksanakan pada 2 (dua) lokasi, yaitu pada bangunan Gedung Direktorat dan Gedung A. Kegiatan yang dilakukan meliputi : studi pustaka, pengujian lapangan, pengumpulan data dan pembuatan laporan. Hasilnya dapat disimpulkan bahwa gradasi kualitas mutu beton pada bangunan-bangunan gedung penunjang pendidikan di 3 (tiga) Politeknik tersebut masih memenuhi standar sehingga dapat dikatakan bahwa keandalan struktur bangunan masih memenuhi untuk laik fungsi.
\end{abstract}

Kata Kunci

Politeknik, struktur, bangunan, gedung, pemeriksaan, pengujian, beton

\section{PENDAHULUAN}

Bangunan gedung merupakan bangunan fisik yang mempunyai peranan penting dalam menunjang aktivitas penggunanya. Bangunan gedung di suatu Politeknik (Gedung Laboratorium, Gedung Perkuliahan, Gedung Rektorat), merupakan contoh bangunan fisik yang berperan penting untuk menunjang pendidikan vokasi. Politeknik Pos, Politeknik Manufaktur dan Politeknik Negeri Bandung merupakan 3 (tiga) Politeknik yang memiliki bangunan fisik yang fungsinya sangat strategis dalam melayani kepentingan pendidikan vokasi, yaitu terselenggaranya proses belajarmengajar mahasiswa politeknik secara memadai. Bangunan di 3 politeknik tersebut umumnya dibangun pada tahun 1980-an, sehingga sudah berumur sekitar 30 tahunan. Usia bangunan yang relatif sudah cukup tua dibandingkan dengan usia pakainya (50 tahun untuk konstruksi beton) dan pemanfaatan bangunan untuk bengkel dan laboratorium (yang berarti beban yang diterima bangunan cukup besar) serta pemeliharaan yang ala kadarnya, mengakibatkan bangunan untuk pendidikan politeknik banyak mengalami kerusakan (Marlailana, E.RR, Juarti, E.R dan Noorlaelasari, Y., 2016) [1]. Menurut Kristianto, Usman (2009) [2], terdapat 3 (tiga) klasifikasi kerusakan bangunan yaitu, kerusakan ringan, kerusakan sedang ataupun kerusakan berat. Kerusakan bangunan ini sebetulnya masih dapat ditolerir sampai batas umur rencana, namun sebelum suatu bangunan sampai pada batas umur pakai, biasanya telah terjadi kerusakan. Oleh karena itu, agar bangunan dapat berfungsi dengan baik, maka perlu diidentifikasi besarnya tingkat kerusakan yang terjadi (baik terkait material/bahan pembentuknya maupun struktur penopangnya), salah satu langkah yang dapat dilakukan adalah dengan melakukan pemeriksaan dan pengujian 
terhadap material/bahan pembentuknya untuk mengetahui ketahanan kontruksi bangunan gedung selama masa layan tertentu. Salah satu material pembentuk struktur bangunan gedung adalah beton. Untuk mengetahui kekuatan beton pada suatu struktur bangunan, maka perlu dilakukan pengujian dan evaluasi terhadap kuat tekan dari beton yang digunakan.

\section{TINJAUAN PUSTAKA}

Didalam mengevaluasi kekuatan beton, compression test menjadi standar untuk mengetahui kualitas suatu struktur secara keseluruhan (Setjo, R., 2012) [3]. Kualitas beton dapat dilakukan dengan dua metode pengujian yaitu metode dengan merusak benda uji (Destructive Test/DT) dan metode tanpa merusak benda uji (Non Destructive Test/NDT). Metode NDT sangatlah bervariasi di dalam sistem kerja maupun alat yang digunakan untuk uji kekuatan beton, untuk mengevaluasi keandalan struktur digunakan Metode Ultrasonic Pulse Velocity (UPV) atau kecepatan pulsa ultrasonik. Peralatan yang digunakan untuk pengujian tersebut adalah dengan alat PUNDIT (Portable Ultrasonic Non-destructive Digital Indicator Tester). Ultrasonic Pulse Velocity (UPV) adalah metode yang digunakan untuk mengukur kecepatan hantaran dari gelombang (pulse velocity) ultrasonik yang melewati suatu beton.

Menurut Saja, S (2008) [4], alat uji PUNDIT (Portable Ultrasonic Non-destructive Digital Indicator Tester) direncanakan untuk mengukur waktu rambatan yang dinyatakan dalam micro detik dari rambatan gelombang ultrasonik melalui beton. Pengukuran besaran ini ternyata sangat penting untuk memperoleh informasi mengenai kondisi fisik dan mekanik dari bangunan melalui prosedur-prosedur penyelidikan Non Destructive, seperti indikasi adanya : patahan-patahan (retak mikro, cacat sarang tawon, rongga udara); pertumbuhan kerusakan akibat api; kandungan bahan lain (seperti : serpihan kayu, polystyrene atau kertas); kekuatan tekan beton; modulus elastisitas beton dan keseragaman pengecoran beton. Standar atau prosedur dalam menggunakan metode pengujian ini dapat dilihat pada ASTM C 597 [5]. Kriteria dari hasil pengukuran kecepatan pulsa ultrasonik dapat dilihatpada tabel1 di bawah ini.

Tabel 1. Kriteria Kecepatan Pulsa

\begin{tabular}{|c|c|c|}
\hline No & $\begin{array}{c}\text { Pulse Velocity } \\
(\mathrm{Km} / \mathrm{sec})\end{array}$ & $\begin{array}{c}\text { Concrete Quality } \\
\text { Grading }\end{array}$ \\
\hline 1 & Above 4.5 & Excellent \\
\hline 2 & $3.5-4.5$ & Good \\
\hline 3 & $3.0-3.5$ & Medium \\
\hline 4 & Below 3.0 & Doubtful \\
\hline
\end{tabular}

Sumber: IS 13311 (Part 1) : 1992

\section{TUJUAN PENELITIAN}

Berdasarkan uraian di atas, maka dapat disampaikan beberapa tujuan penelitian sebagai berikut :

1. Melakukan pengujian tidak merusak dengan Metode Ultrasonic Pulse Velocity (UPV) atau kecepatan pulsa ultrasonik pada Bangunan Gedung Penunjang Pendidikan di Politeknik Pos, Politeknik Manufaktur dan Politeknik Negeri Bandung.

2. Mengetahui kualitas mutu beton pada elemen kolom dan balok pada Bangunan Gedung Penunjang Pendidikan di Politeknik Pos, Politeknik Manufaktur dan Politeknik Negeri Bandung.

\section{METODE PENELITIAN}

\subsection{Lokasi Pengambilan Data dan Alat Uji yang Digunakan}

Lokasi pengambilan data dilaksanakan di 3 (tiga) Politeknik, yaitu Politeknik Pos, Politeknik Manufaktur dan Politeknik Negeri Bandung. Pada bangunan gedung di Politeknik Pos dilaksanakan pada 2 (dua) lokasi, yaitu pada bangunan Gedung Rektorat dan Gedung Pendidikan masing-masing terdiri dari 3 lantai. Pada bangunan gedung Politeknik Manufaktur dilaksanakan pada satu lokasi, yang terdiri dari Gedung Rektorat, Gedung Kuliah dan Gedung Administrasi. Pada bangunan gedung Politeknik Negeri Bandung dilaksanakan pada 2 (dua) lokasi, yaitu pada bangunan Gedung Direktorat dan Gedung A. Kegiatan meliputi : studi pustaka, pengujian lapangan, pengumpulan data dan pembuatan laporan. Proceq Pundit Lab merupakan jenis alat yang digunakan untuk penelitian ini dengan standar yang diacu adalah EN 12504-4, ASTM C59702, BS 1881 : Part 203, ISO 1920-7:2004, IS13311 dan CECS21.

\subsection{Proses Pengujian di Lapangan}

Pengujian pada bangunan gedung di 3 (tiga) Politeknik tersebut dilaksanakan pada elemen kolom dan balok. Tahap pengujian terdiri dari persiapan alat dan bidang uji yang akan diuji. Bidang uji pada elemen struktur harus merupakan permukaan yang padat, kering dan halus, bebas dari tonjolan-tonjolan atau lubanglubang, serta lokasi-lokasi bidang uji harus ditentukan sesuai dengan dimensi elemen struktur dan jumlah nilai uji yang diperlukan untuk perhitungan perkiraan kecepatan 
hantaran dari gelombang (kecepatan rambat gelombang/ pulse velocity).

Alat ini bekerja berdasarkan pengukuran waktu tempuh gelombang ultrasonik yang menjalar dalam struktur beton. Langkah yang pertama dilakukan adalah dengan menempelkan unit sensor ke permukaan beton, yang akan memancarkan gelombang dari transmitter menuju ke receiver. Karena kecepatan rambat gelombang adalah merupakan fungsi dari kepadatan material, maka dengan diketahuinya cepat rambat gelombang (pulse velocity) ultrasonik di dalam beton, kecepatan tersebut dapat dikorelasikan ke nilai kepadatan beton, yang selanjutnya dikorelasikan lagi ke mutu beton, berdasarkan grafik empiris hubungan kecepatan rambat gelombang dengan mutu beton. Kecepatan rambat gelombang (pulse velocity)ini, akan ditampilkan dan bisa dibaca pada display. Setelah itu dengan merujuk pada Tabel 1, maka kriteria kualitas mutu beton pada elemen bangunan yang diuji dapat diketahui.

\section{HASIL DAN PEMBAHASAN}

\subsection{Bangunan Gedung Politeknik Pos}

Pengujian struktur beton bertulang dengan Proceq Pundit Lab pada bangunan gedung di Politeknik Pos dilaksanakan pada 2 (dua) lokasi, yaitu pada bangunan Gedung Rektorat dan Gedung Pendidikan masing-masing terdiri dari 3 lantai. Pengujian pada kedua bangunan gedung tersebut hanya dapat dilaksanakan pada elemen kolom, karena elemen yang lainya (seperti balok) tertutup atau terhalang oleh plafon.

Pada Gambar 1, menunjukan nilai Pulse Velocity kolom dari hasil pengujian pada lantai 1, 2, dan 3 bangunan Gedung Rektorat. Dari gambar tersebut terlihat bahwa nilai Pulse Velocity kolom, nilainya di atas $4.5 \mathrm{Km} / \mathrm{sec}$. Hal ini menunjukan bahwa mutu beton pada elemen kolom tersebut mutunya sangat baik.

Sementara pada Gambar 2, menunjukan nilai Pulse Velocity kolom dari hasil pengujian pada lantai 1, 2, dan 3 bangunan Gedung Pendidikan. Dari gambar tersebut terlihat bahwa nilai Pulse Velocity kolom pada lantai dasar dan lantai 1 , nilainya diantara 3.5 - 4.5 $\mathrm{Km} / \mathrm{sec}$. Hal ini menunjukan bahwa mutu beton pada elemen kolom pada lantai tersebut, mutunya pada kategori baik. Sedangkan kolom pada lantai 2, nilainya diantara 3.0 - 3.5 $\mathrm{Km} / \mathrm{sec}$ yang menunjukan masih memenuhi standar.

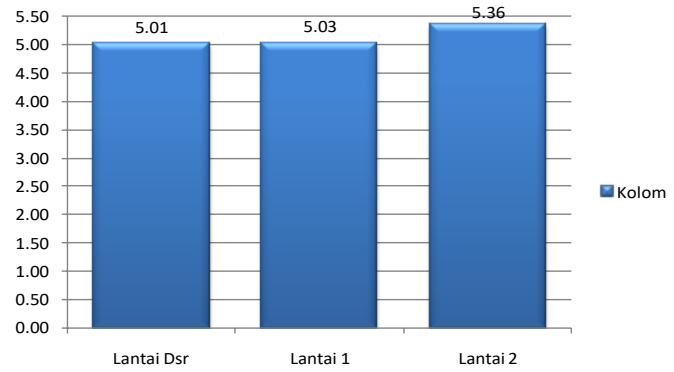

Gambar 1. Gedung Rektorat - Politeknik Pos

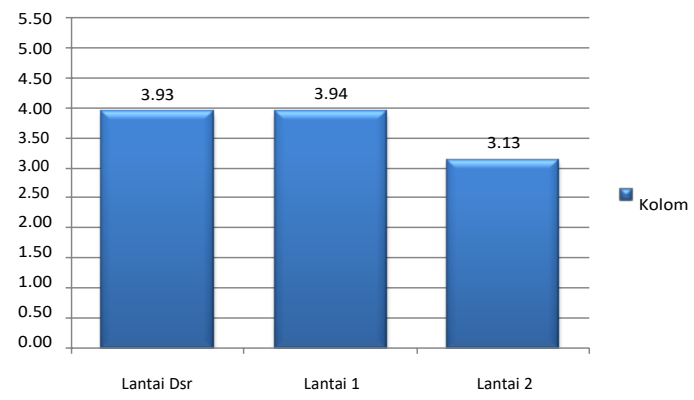

Gambar 2. Gedung Pendidikan - Politeknik Pos

\subsection{Bangunan Gedung Politeknik Manufaktur}

Pengujian struktur beton bertulang pada bangunan gedung di Politeknik Manufaktur dilaksanakan pada satu lokasi, yang terdiri dari Gedung Rektorat, Gedung Kuliah dan Gedung Administrasi. Pengujian pada bangunan gedung-gedung tersebut dilaksanakan pada elemen kolom dan balok, kecuali balok di lantai 2 pada gedung kuliah tidak dapat dilaksanakan pengujian karena tertutup atau terhalang oleh plafon.

Pada Gambar 3, menunjukan nilai Pulse Velocity kolom dan balok dari hasil pengujian pada lantai 1 dan 2 bangunan Gedung Rektorat. Dari gambar tersebut terlihat bahwa nilai Pulse Velocity kolom pada lantai 1 , nilainya di atas $3.0 \mathrm{Km} / \mathrm{sec}$. Hal ini menunjukan bahwa mutu beton pada elemen kolom tersebut memenuhi standar. Sedangkan untuk kolom pada lantai 2 dan balok pada lantai 1 dan 2, menunjukan bahwa mutu beton pada elemen tersebut, mutunya pada katergori baik karena nilainya diantara 3.5 - 4.5 $\mathrm{Km} / \mathrm{sec}$. 


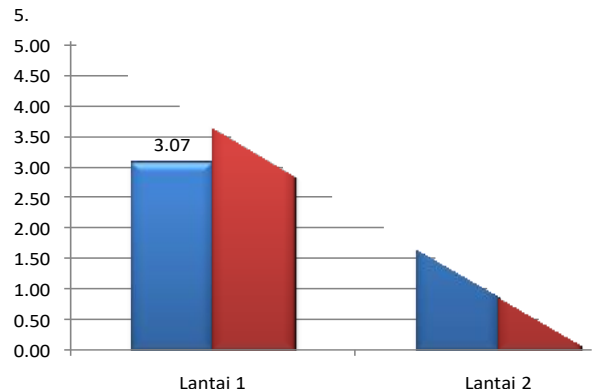

Gambar 3. Gedung Rektorat - Politeknik Manufaktur

Pada Gambar 4, menunjukan nilai Pulse Velocity kolom dan balok dari hasil pengujian pada lantai dasar sampai lantai 3 bangunan Gedung Kuliah. Dari gambar tersebut terlihat bahwa nilai Pulse Velocity kolom dan balok pada masing-masing lantai, nilainya di atas $3.0 \mathrm{Km} / \mathrm{sec}$, kecuali balok pada lantai 2 . Hal ini menunjukan bahwa mutu beton pada elemen kolom dan balok tersebut memenuhi standar.

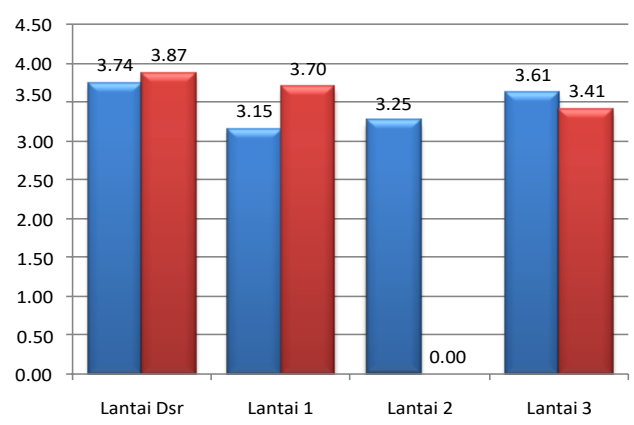

Gambar 4. Gedung Kuliah - Politeknik Manufaktur

Pada Gambar 5, menunjukan nilai Pulse Velocity kolom dan balok dari hasil pengujian pada lantai dasar bangunan Gedung Administrasi. Dari gambar tersebut terlihat bahwa nilai Pulse Velocity kolom dan balok, nilainya di atas $3.0 \mathrm{Km} / \mathrm{sec}$. Hal ini menunjukan bahwa mutu beton pada elemen kolom dan balok tersebut memenuhi standar.

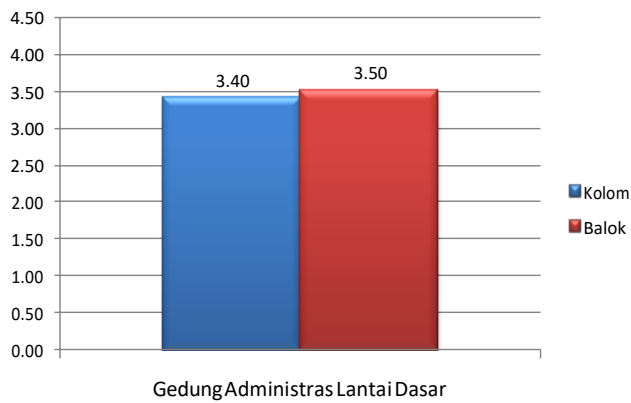

Gambar 5. Gedung Administrasi - Politeknik Manufaktur

\subsection{Bangunan Gedung Politeknik Negeri Bandung}

Pengujian struktur beton bertulang pada bangunan gedung di Politeknik Negeri Bandung dilaksanakan pada 2 (dua) lokasi, yaitu pada bangunan Gedung Direktorat dan Gedung A. Pengujian pada bangunan gedunggedung tersebut dilaksanakan pada elemen kolom dan balok.

Pada Gambar 6, menunjukan nilai Pulse Velocity kolom dan balok dari hasil pengujian pada lantai dasar, 1 dan 2 bangunan Gedung Direktorat. Dari gambar tersebut terlihat bahwa nilai Pulse Velocity elemen kolom dan balok pada masing-masing lantai, nilainya diantara 3.5 - $4.5 \mathrm{Km} / \mathrm{sec}$. Hal ini menunjukan bahwa mutu beton pada elemen kolom dan balok pada lantai tersebut, mutunya pada kategori baik.

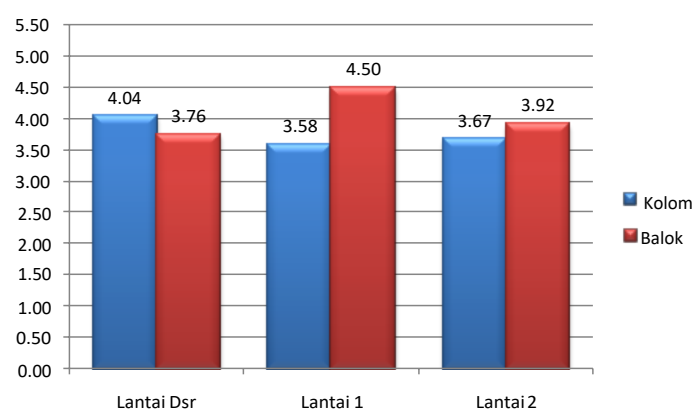

Gambar 6. Gedung Direktorat - Politeknik Negeri Bandung

Pada Gambar 7, menunjukan nilai Pulse Velocity kolom dan balok dari hasil pengujian pada lantai dasar sampai lantai 2 bangunan Gedung A. Dari gambar tersebut terlihat bahwa nilai Pulse Velocity balok pada lantai dasar, kolom lantai 1 dan lantai 2, nilainya diantara 3.0 - $3.5 \mathrm{Km} / \mathrm{sec}$ yang menunjukan bahwa mutu beton masih memenuhi standar. Sedangkan untuk kolom lantai 1, balok lantai 1 dan lantai 2, nilainya diantara $3.5-4.5 \mathrm{Km} / \mathrm{sec}$. Hal ini menunjukan bahwa mutu beton pada elemen kolom dan balok tersebut, mutunya pada kategori baik. 


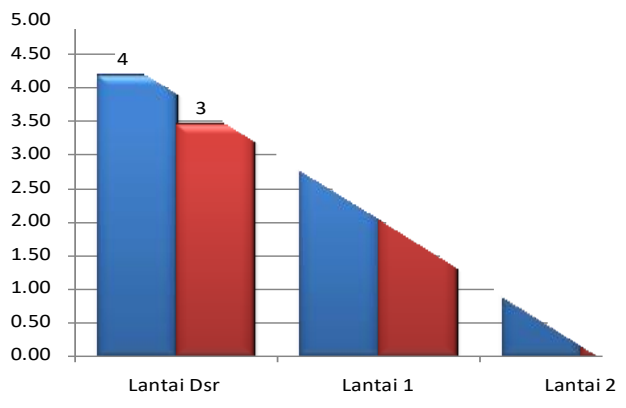

Gambar 7. Gedung A - Politeknik Negeri Bandung

\section{KESIMPULAN DAN SARAN}

\subsection{Kesimpulan}

Standar IS 13311 (Part 1) : 1992 menjelaskan bahwa kualitas mutu beton sangat tergantung dari kecepatan rambat gelombang (Tabel 1), yang dibagi menjadi 4 kriteria yaitu Excellent, Good, Medium dan Doubtful. Kecepatan pulsa tidak tergantung pada geometri dari bahan beton dan hanya bergantung pada sifat elastisitasnya. Kualitas mutu beton yang baik, dalam hal ini kepadatan, homegenitas dan keseragam, akan diperoleh nilai kecepatan rambat gelombang (Pulse Velocity) yang lebih tinggi. Tetapi sebaliknya, bila kualitas mutu beton rendah akan diperoleh nilai kecepatan rambat gelombang (Pulse Velocity) yang rendah.

Pada tabel di bawah ini merupakan ringkasan dari hasil-hasil pengujian struktur beton bertulang dengan Metode Ultrasonic Pulse Velocity (UPV) atau kecepatan rambat gelombang ultrasonik sebagai berikut:
Tabel 2. Hasil pengujian struktur beton bertulang dengan Metode Ultrasonic Pulse Velocity (UPV)

\begin{tabular}{|c|c|c|c|c|c|}
\hline \multirow{2}{*}{ No } & \multirow{2}{*}{$\begin{array}{l}\text { Nama } \\
\text { Gedung }\end{array}$} & \multicolumn{4}{|c|}{$\begin{array}{l}\text { Gradasi mutu beton } \\
\text { pada elemen kolom }\end{array}$} \\
\hline & & $\begin{array}{l}\text { Lantai } \\
\text { Dasar }\end{array}$ & Lantai 1 & Lantai 2 & Lantai 3 \\
\hline 1 & $\begin{array}{l}\text { Politeknik } \\
\text { Pos: } \\
\text { a. Ged } \\
\text { Rektorat } \\
\text { b.Ged } \\
\text { Pendidikan } \\
\end{array}$ & $\begin{array}{c}\text { Excellent } \\
\text { Good }\end{array}$ & $\begin{array}{c}\text { Excellent } \\
\text { Good }\end{array}$ & $\begin{array}{l}\text { Excellent } \\
\text { Medium }\end{array}$ & $\begin{array}{l}- \\
-\end{array}$ \\
\hline 2 & $\begin{array}{l}\text { Politeknik } \\
\text { Manufaktur: } \\
\text { a. Ged } \\
\text { Rektorat } \\
\text { b. Ged Kuliah } \\
\\
\text { c. Ged } \\
\text { Rektorat } \\
\end{array}$ & $\begin{array}{c}- \\
\text { Good } \\
\text { Medium }\end{array}$ & $\begin{array}{c}\text { Medium } \\
\text { Medium } \\
-\end{array}$ & $\begin{array}{c}\text { Good } \\
\text { Medium } \\
-\end{array}$ & $\begin{array}{c}- \\
\text { Good } \\
-\end{array}$ \\
\hline 3 & $\begin{array}{l}\text { Politeknik } \\
\text { Negeri } \\
\text { Bandung: } \\
\text { a. Ged } \\
\text { Direktorat } \\
\text { b.Gedung A }\end{array}$ & $\begin{array}{l}\text { Good } \\
\text { Good }\end{array}$ & $\begin{array}{c}\text { Good } \\
\text { Medium }\end{array}$ & $\begin{array}{l}\text { Good } \\
\text { Good }\end{array}$ & - \\
\hline
\end{tabular}

\begin{tabular}{|c|l|c|c|c|c|}
\hline \multirow{2}{*}{ No } & \multicolumn{1}{|c|}{$\begin{array}{c}\text { Nama } \\
\text { Gedung }\end{array}$} & \multicolumn{4}{|c|}{$\begin{array}{c}\text { Gradasi mutu beton } \\
\text { pada elemen balok }\end{array}$} \\
\cline { 2 - 6 } 1 & $\begin{array}{l}\text { Lantai } \\
\text { Dasar }\end{array}$ & Lantai 1 & Lantai 2 & Lantai 3 \\
\hline & $\begin{array}{l}\text { Politeknik } \\
\text { Pos: } \\
\text { a. Ged } \\
\text { Rektorat } \\
\text { b. Ged } \\
\text { Pendidikan }\end{array}$ & - & - & - & - \\
\hline \multirow{2}{*}{2} & $\begin{array}{l}\text { Politeknik } \\
\text { Manufaktur: } \\
\text { a. Ged } \\
\text { Rektorat } \\
\text { b. Ged } \\
\text { Kuliah } \\
\text { c. Ged } \\
\text { Rektorat }\end{array}$ & - & - & - & - \\
\hline Politeknik & $\begin{array}{l}\text { Medium } \\
\text { Begeri } \\
\text { Bandung: } \\
\text { a. Ged } \\
\text { Direktorat } \\
\text { b. Gedung A }\end{array}$ & Goodium & Good & - & Medium \\
\hline
\end{tabular}

Dapat disimpulkan bahwa gradasi kualitas mutu beton pada bangunan-bangunan gedung penunjang pendidikan di 3 (tiga) Politeknik, yaitu Politeknik Pos, Politeknik Manufaktur dan Politeknik Negeri Bandung, masih memenuhi standar sehingga dapat dikatakanbahwa keandalan struktur bangunan masih memenuhi untuk laik fungsi 


\subsection{Saran}

Meskipun hasil pengujian menunjukkan bahwa keandalan struktur bangunan masih memenuhi untuk laik fungsi, namun diperlukan serangkaian prosedur pengujian lain dengan tujuan mengevaluasi struktur secara menyeluruh, tidak hanya kekuatan struktur betonnya saja tetapi juga mendeteksi keberadaan tulangan yang ada pada beton terpasang meliputi jumlah tulangan, dimensi tulangan, serta tata letak tulangannya.

Sebaiknya dilakukan juga pengujian "Hammer Test" dan "Rebar Locator" untuk melengkapi evaluasi struktur bangunan secara menyeluruh. Mengingat usia bangunan politeknik yang relatif cukup tua (sekitar 30 tahunan), maka proses pemeliharaan dan perawatan juga perlu mendapat perhatian utama. Dari hasil pengujian beberapa bagian bangunan dengan kriteria "Good", perlu mandapat perhatian khusus. Karena jika tidak dilakukan pemeliharaan dan perawatan yang intensif, maka lama-kelamaan kualitas mutu beton akan semakin menurun, yang berimbas pada menurunnya fungsi layan dan banyaknya kerusakan komponen material dari bangunan itu sendiri, hal ini mengakibatkan bangunan tidak dapat lagi berfungsi lagi dan umurnya tidak sesuai lagi dengan usia pakai yang direncanakan (biasanya 50 tahun untuk konstruksi beton).

\section{DAFTAR PUSTAKA}

[1] Marlailana, E.RR, Juarti, E.R dan Noorlaelasari, Y., Kajian Indikator Kinerja Bangunan Gedung Akibat Kerusakan Fisik dan Pengaruh Umur Bangunan. Laporan PenelitianFundamental, Politeknik Negeri Bandung,2016.

[2] Usman, K.,Kajian Manajemen Pemeliharaan Gedung (Building Maintenance) di Universitas Lampung, Universitas Lampung,2009.

[3] Setjo R., Perkiraan Kekuatan Beton Pasca Gempa Dengan Metode Uji Tak Rusak, Prosiding Seminar BPPT, Yogyakarta, 2012.

[4] Saja S., Investigasi Keandalan dan Perbaikan Struktur Beton Bertulang. Studi Kasus : Oxy Hydro Chlorine Reaktor Plant PT. Asahimas Chemical, Anyer Cilegon, Tugas Akhir Universitas Mercu Buana, Jakarta, 2008.
[5] ASTM 1997 C 597-83, 1991, Standard Test Method For Pulse Velocity Through Concrete.

[6] Apriani W., 2016. Aplikasi Non Destructive Test pada Investigasi Keandalan Struktur Beton (Studi Kasus : Kolom Basement - K4 Pada Bangunan Stadion Utama Riau), Jurnal Teknik Sipil Siklus, Vol 2 (No. 2), Oktober 2016.

[7] Juarti, E.R. dan Rahmitasari., Buku Ajar Perawatan Bangunan 1 (NDT Series), Jurusan Teknik Sipil, Politeknik Negeri Bandung, 2013.

[8] Marlailana, E.RR, Juarti, E.R dan Noorlaelasari, Y., Bahan Aajar Pemeriksaan dan Pengujian untuk Mendeteksi Kerusakan Bangunan Gedung. Jurusan Teknik Sipil, Politeknik Negeri Bandung, 2014.

[9] Ruslan, U. dan Kasyanto. Heri., Buku 1 Bahan Ajar Perawatan Bangunan 2 (NDT Series), Jurusan Teknik Sipil, Politeknik Negeri Bandung, 2013. 